\title{
Mapping the Future: \\ Policy Applications of Climate Vulnerability Mapping in West Africa
}

\begin{abstract}
We describe the development of climate vulnerability maps for three Sahelian countries - Mali, Burkina Faso, and Niger - and for coastal West Africa, with a focus on the way the maps were designed to meet decision-making needs and their ultimate influence and use in policy contexts. The paper provides a review of the literature on indicators and maps in the science-policy interface. We then assess the credibility, salience, and legitimacy of the maps as tools for decision-making. Results suggest that vulnerability maps are a useful boundary object for generating discussions among stakeholders with different objectives and technical backgrounds, and that they can provide useful input for targeting development assistance. We conclude with a discussion of the power of maps to capture policy maker attention, and how this increases the onus on map developers to communicate clearly uncertainties and limitations. The assessment of policy uptake in this paper is admittedly subjective; the article includes a discussion of ways to conduct more objective and rigorous assessments of policy impact so as to better evaluate the value and use of vulnerability mapping in decision-making processes.

Keywords: climate change, vulnerability mapping, hotspots mapping, decision support tools, spatial assessment
\end{abstract}

This is the accepted version of the following article:

de Sherbinin, A., A. Apotsos, and J. Chevrier. 2017. Mapping the Future: Policy Applications of Climate Vulnerability Mapping in West Africa. The Geographical Journal. 183(4): 414-425.

It has been published in final form at: https://doi.org/10.1111/geoj.12226. This article may be used for non-commercial purposes in accordance with the Wiley Self-Archiving Policy. 


\section{Introduction}

Research on climate change vulnerability, defined as the susceptibility and adaptive capacity of societies and systems to the impacts of climate variability and change, is proliferating (PROVIA 2013). Within that broader research space, spatial vulnerability assessment illuminates patterns of historical vulnerability and risk to climatic factors, as well as likely future vulnerability under climate change. The demand for vulnerability maps among development agencies and governments is increasing as greater emphasis is placed on scientifically sound methods for targeting adaptation assistance (de Sherbinin 2013 and 2014a; Preston et al. 2011). Mapping is useful because climate variability and extremes, the sensitivity of populations and systems to climatic stressors, and adaptive/coping capacities are all spatially differentiated. The interplay of these factors often produces complex spatial patterns of vulnerability that vary over different scales. Often spatial vulnerability assessment involves data integration in which georeferenced socio-economic and bio-physical data are combined with climate data and projections to understand patterns of vulnerability and, in turn, inform where adaptation may be required (e.g., de Sherbinin et al. 2015, 2014a and 2014b; Midgley et al. 2011; Busby et al. 2011). Maps have proven to be useful boundary objects in multi-stakeholder discussions, providing a common basis for discussion and for deliberations over adaptation planning (Preston et al. 2011). Maps can help to ground discussions on a solid evidence base, especially in developing country contexts where geographic information may not be easily accessible for all stakeholders.

The power of spatial assessment is that it presents a large amount of often complex information in a simplified and visually attractive manner. Yet this strength can also be a weakness, insofar as uncertainties in the data and important analyticalal assumptions that affect map outputs are often hidden from the user. This paper assesses vulnerability mapping for decision support by the U.S. Agency for International Development (USAID) in West Africa. West Africa is considered a hotspot of climate 
vulnerability relative to other world regions owing to combinations of high poverty and population growth, weak institutions, and high climate variability (López-Carr et al. 2014; de Sherbinin 2013). The region has already experienced warming temperatures and changing precipitation patterns (Turco et al. 2015; USGS \& USAID 2012), and climate projections suggest significant changes in the future that could severely affect agricultural and pastoral systems (Blarney et al. 2013).

The paper assesses the policy uptake of vulnerability mapping for the Sahelian countries of Mali, Niger, and Burkina Faso, and coastal exposure mapping focused on sea level rise and coastal flooding for the coastal zone stretching from Guinea-Bissau to Cameroon. We first present a brief literature review on the role and utility of indicators and maps in the science-policy interface, before turning to demand for the maps and their use by end users at USAID, its development partners, and partner governments. We assess the map products in terms of their credibility, salience and legitimacy among stakeholders (Cash et al. 2003). This article seeks to contribute to the literature on climate vulnerability 'hotspot' mapping by evaluating the process, results and ultimate policy uptake and influence of the maps in programme planning. A summary of the methods used to develop the maps is found in de Sherbinin et al. (2015).

This article has five main sections. The next provides a literature review on indicators, maps and the science-policy interface, while the third describes the policy uptake of mapping in three countries Mali, Niger, and Burkina Faso - as well as a broader mapping of coastal West Africa stretching from Guinea in the West to Cameroon in the East. In the penultimate section we discuss the results, before a concluding section.

We acknowledge that this is a subjective assessment, in that while the authors were directly involved in the map development and interactions with policy audiences, they have not researched in detail the processes whereby maps take effect in policy. However, the paucity of literature in this area 
(Preston et al. 2009 represents one of very few examples), and the importance of vulnerability mapping for the spatial targeting of adaptation activities and development investments for those most in need, mean that documenting experiences in this domain is important and that lessons need to be shared more widely. The authors' direct engagement with the end users can also be considered a strength, in that it opens a door of understanding of how these maps are ultimately perceived and used by decision making audiences. We propose some approaches for more rigorous assessment of policy impacts at the end of the Discussion section.

\section{Indicators, Maps and the Science-Policy Interface}

There has been a rapid expansion in the development and use of indicators and indices (where an index comprises a number of indicators) to inform environmental policy and management decisions in the past few decades (de Sherbinin et al. 2014c), and demand for climate adaptation planning has led to increased development of climate-related indicators (e.g. USGCRP 2012a and 2012b). An example of a composite indicator-based map produced for USAID is provided in Supplementary Information as Figure SI1. Spatial vulnerability indicators and indices can be thought of as a special case of socio-ecological indicators that integrate the human and the natural system, and which map the indicators spatially using either administrative units or grid cells. Here we begin with an overview of how environmental indicators are used in the policy process, then address debates around the feasibility of measuring vulnerability using indicators. Finally, we discuss the role of maps in decision making, and introduce the science-policy framework we use in the evaluation of the West African vulnerability mapping efforts.

Environmental indicators and indices can help to reduce complexity in policy-relevant ways, providing an important link between science and policy and helping to point decision-makers towards potential solutions to problems at the human-environment interface. In a review of the interaction between decision makers and science providers, McNie (2006:17) writes, "Useful scientific information 
... improves environmental decision-making by expanding alternatives, clarifying choice and enabling decision makers to achieve desired outcomes." In the quest to create and provide useful scientific information, indicators have the potential to distill information from large and complex data streams, simplifying an otherwise complex reality (Abson et al. 2012).

The most direct role that indicators play in the policy process is in the synthesis and communication of complex data and phenomena, such as sustainability and vulnerability (OECD 2008). In the theory and study of the policy process, policy learning (the study of the design, operation and impacts of policies) depends on a number of events, of which the generation and incorporation of information (i.e., data) into policy decisions is a critically important one (Sabatier and Jenkins-Smith, 1993). It is no surprise then that incorporating accurate data into policy decisions is a near necessity in the environmental arena, where linkages are complex, science is typically incomplete, and uncertainty is high (Bradshaw and Borchers 2000). Indeed indicators and indexes may be particularly useful in the environmental and climate adaptation arenas, where the complexity of the science and uncertainty over long term impacts or cause and effect is often held as a reason for inaction or indecision. Referring to what they call the "science-policy gap", Bradshaw and Borchers (2000: 1) write, "Generally speaking, whereas scientists may be familiar with the conditions of scientific uncertainty, the public and policy makers often seek certainty and deterministic solutions." What this suggests is that it is important to balance transparency about the uncertainty in indicators and indices with the policy makers' need for "concrete information" upon which to base decisions.

Indicators synthesize knowledge needed for policy learning by serving as a conduit to integrate data into planning, to set and track progress towards goals, to determine the levels and scales of implementation and policy action, and to inform and assess specific decisions, general policy directions, and community values (Hezri 2004). The European Union funded Policy Use and Influence of Indicators 
(POINT) project, in its examination of the role and influence of indicators in the European policy context, found that indicators play three primary roles (POINT 2011): (1) an instrumental role (e.g., the direct use of indicators to monitor conditions or programmes or to target resources), (2) a conceptual role (e.g., the use of indicators to frame issues), and (3) a political role (e.g., where indicators are used to legitimize policies or policy actors). Vulnerability mapping primarily plays an instrumental role, but also undoubtedly has conceptual and political roles. A framework is needed to integrate underlying indicators into an overall vulnerability index, and these frameworks are guided by theories on how the indicators interrelate. Klein (2009) also notes that there is also a political aspect to vulnerability mapping: with billions of dollars in adaptation funding at stake, there is a financial incentive for countries or regions to portray themselves as highly vulnerable to climate impacts.

While it is widely recognized that vulnerability mapping is vitally important for adaptation planning (PROVIA 2013), there is general agreement that measuring and mapping vulnerability is challenging (e.g., de Sherbinin 2014b). For example, Hinkel (2011) argues that, for most purposes, vulnerability as a concept cannot be adequately quantified, while Birkman and Wisner (2006) suggest that despite the need for measurement, there is a sense in which vulnerability is unmeasurable. Vulnerability has been termed an "emergent phenomenon", in that it emerges from the stresses on the system, and therefore cannot be directly measured (Nelson et al. 2010). Generally, a stressor, such as a major storm or flood, is said to reveal the underlying vulnerabilities of the coupled human-environment system through outcome measures, such as excess mortality or economic losses. As stated earlier, the strength of indicators and indices is information reduction that, ideally, separates the signal from the noise. Yet, there is an inherent tradeoff between the richness of information and the complexity of the real world, on the one hand, and the communicability and utility of that information for policymaking, 
on the other (Abson et al. 2012). In the case of vulnerability - a complex, multi-causal emergent phenomenon - these tradeoffs are accentuated.

Furthermore, because vulnerability cannot be measured directly, it involves a process of identifying "indicating variables", which point to the construct of vulnerability, and then aggregating them (Hinkel 2011). However, our theoretical understanding of what exactly produces vulnerability (i.e. the interrelationships among variables) is often inadequate for a robust index construction. While variables such as changes in temperature and precipitation, poverty levels and malnutrition rates, education levels and institutional capacity may all be used to measure aspects of vulnerability, they are at best proxies. Beyond the inadequacy of the proxies and frequent data gaps, a further challenge is that we do not fully understand how these variables interrelate. Are some more important than others (implying differential weights)? Are there thresholds or feedbacks? And should they be aggregated using an arithmetic mean, or a geometric mean to imply that poor performance on one or more indicators cannot be offset by above-average performance on others?

Reconciling the demand for vulnerability indices and maps on the part of the policy community (PROVIA 2013; BMZ 2014; Preston et al. 2011), their potential utility for identifying those most vulnerable to climate change, and the very real challenges in measurement, is a balancing act facing academics interested in mapping these complex socio-ecological systems. At a minimum, it requires humility together with a high level of methodological transparency and a clear communication of the uncertainty and limitations.

Map communication in policy contexts brings its own particular set of challenges, and the subject of geospatial decision support tools has a long literature (e.g., Feick and Hall 2001, Densham 1991). Maps, like indicators, require the simplification of complex realities by strategically removing information so as to draw the reader's attention to the main communication objective. Yet, Preston et 
al. (2011: 178) point out, "there is also evidence that the power of maps has cultivated a bias regarding their inherent utility", and Monmonier (1991) suggests that few users consider the map's power as a tool of subtle propaganda. Despite this, there has been surprisingly little literature on the influence of maps on public policy (an issue to which we return at the end of the Discussion section), or on the degree to which decision makers possess the map reading skills to understand the often complex information presented, particularly in the case of climate vulnerability maps.

While it is tempting to conclude that vulnerability mapping is a fool's errand that should best be left to commercial firms that service naïve policy audiences, it can equally well be argued that academic engagement in the generation of maps for adaptation decision making is vital, since millions of dollars of adaptation funding are already flowing, with potentially billions more in the pipeline, and spatial prioritization is critical. We contend that it is vital to cultivate an awareness of the uncertainties in the maps among end users while simultaneously recognizing the potential benefits they provide in targeting those with the greatest needs. This is a subject we return to in the Conclusion.

In the remainder of this paper we assess the demand for and use of the map products for USAID regional programmeming in West Africa, evaluating them in terms of three aspects that are important to the use of information in policy processes: credibility, salience and legitimacy (Cash et al. 2003; Cook et al., 2013; Chaudhury et al. 2014). In accordance with the literature, we define these three characteristics as follows. Credibility refers to the perceived technical quality or adequacy of technical evidence by users of scientific information. Findings perceived as having high technical quality are likely to be more compelling to a decision maker. Salience refers to the perceived relevance of the technical information provided to decision makers, and the degree to which it resonates or "strikes a chord" with the intended audience (Hezri and Dovers 2006). If scientific documents do not provide information needed by decision makers in a timely manner and in a language that connects to their needs, then the 
relevance of the scientific information could be lost. Finally, legitimacy refers to the process of collecting scientific information through participation of various actors. Legitimacy is established when scientists and decision makers include a wide range of perspectives to corroborate the design and validate the findings thus generating what is often referred to as "buy-in". Taken together, scientific contributions to policy processes will more likely to be acted upon if they do well in all three aspects.

\section{The Policy Influence of the West Africa Vulnerability Maps}

As laid out in its Climate Change and Development Strategy, launched in January 2012, USAID seeks to use analytical tools to guide its approach to addressing the consequences of climate change. USAID is doing this in part by "support[ing] vulnerability assessments both as sector specific analysis (for example, in food security) and as part of countrywide planning processes (such as by consideration in country development cooperation strategies to help identify where USAID should focus investments)" (USAID 2012, p.17). Based on the understanding that vulnerability to climate change is context specific, differs among individuals, groups, and communities, and varies in both space and time (e.g., Tschakert 2007; Antwi-Agyei et al. 2013), USAID decided to conduct a number of vulnerability assessments across Africa, employing different methodologies as appropriate to the specific circumstances. In most cases, these assessments were conducted to develop a more analytical and robust understanding of climate change impacts and adaptation options in order to inform both the development of climate change specific programmes as well as to inform other development programmes and larger strategic planning processes. In this section we review the policy-making context and the role of the maps in each country; in the following section we assess results using the three criteria of credibility, salience and legitimacy.

As the first in a series of vulnerability studies, the Mali vulnerability maps were initially intended to be used as an internal document by USAID to better understand and visualize how vulnerability 
varied spatially throughout the country. At the time, USAID was beginning the strategic planning process for the development of a new climate change programme, and these maps were viewed as an input to help identify the scale and possible geographic targeting of this programme given the differences in climate and livelihoods stretching from the Sahara desert in the north to the more temperate climate in the south of Mali.

USAID requested that the maps cover as much of the populated areas of the country as possible as they were seeking to understand where the highest relative vulnerability to climate change existed. A strong emphasis was placed on the agricultural sector, especially rainfed agriculture, given its importance to the Malian economy and a significant proportion of the rural population. We used the IPCC framework (Parry et al. 2007) in which vulnerability is construed as emanating from exposure, sensitivity and a lack of adaptive capacity (Figure 1). Given that these maps were requested to inform specific ongoing processes, their development was constrained by the timelines of these processes, including two already scheduled strategic planning meetings in Bamako in October-November 2013. To be useful, these maps needed to be completed prior to those meetings.

\section{[FIGURE 1 HERE]}

During the first meeting at the end of October, USAID staff began conceptualizing the development of a new climate change programme for Mali. The second meeting at the beginning of November involved a larger set of participants and focused on developing ways to build resilience more broadly in Mali. Therefore, the salience of the products was high, and the maps, including maps of input data layers, were used extensively throughout both meetings.

The maps were used as an important input to discussions associated with the general geographic targeting of the new climate change programme within Mali, mostly focused at the regional level, as well as in technical discussions associated with the factors underlying the geographic variations. 
Geographic targeting was important to ensure the limited resources available could achieve significant, but measureable results. The maps were primarily used as a way to facilitate discussions around how climate change interacted with other sectors, such as health and governance, in different parts of Mali. These broader discussions helped identify geographic areas where synergies could be developed between USAID's different development and humanitarian programmes.

The maps helped facilitate these discussions by providing all relevant stakeholders a common framework (i.e., a map) with which they were comfortable, which helped overcome technical jargon and associated communication challenges. For example, by laying the climate change maps next to maps of malnutrition rates it was possible to identify easily areas where both climate change and health programming could be prioritized and coordinated. This use of maps confirms findings from other work in which maps are found to be useful boundary objects for generating discussions among people with different disciplinary backgrounds or portfolios (de Sherbinin 2014b; Preston et al. 2011).

The vulnerability maps confirmed an intuition that areas in the north were more vulnerable to climate change and variability than southern areas. At the time, the country was also just emerging from a major political and military crisis in which large areas of the north seceded from the republic. Given climate and political considerations, it was decided to focus the climate change programme and broader resilience-building efforts in the region of Mopti, a densely settled region in the north-central part of Mali with moderately high climate vulnerability.

A full technical report (de Sherbinin et al. 2014b) provided information on data sources, transformations applied to each indicator, and any uncertainties in the underlying data. This report allowed technical staff to gain the in-depth understanding of the uncertainties and limitations of the maps needed to convey these verbally to those decision-makers. 


\section{Niger and Burkina Faso}

The Mali vulnerability maps had an important demonstration effect, and within a year USAID missions in Niger and Burkina Faso had requested similar maps (see Figure SI1 for the Niger map), also with a focus on the agricultural sector. In line with USAID's current thinking, vulnerability was framed as a chronic lack of resilience. Zones with the most overlap of negative humanitarian and development related indicators combined with high exposure to recurrent climatic and food price shocks were considered to be the most vulnerable.

The map products were presented to in-country stakeholders in Niger (March 2014) and Burkina Faso (February 2015). In Niger, many stakeholders at first mistakenly assumed that it represented another way to map populations at risk to food insecurity, which is the purpose of FEWSNET and the Niger National Early Warning System (SAP) maps. This was based on a misunderstanding about the difference between climate change or structural vulnerability (i.e., the underlying conditions that make places more likely to be vulnerable), and realized vulnerability that is produced by a particular confluence of events or circumstances at a particular point in time - the focus of FEWSNET, SAP and the World Food Programme (WFP) Vulnerability Analysis and Mapping (VAM) exercises. The Niger vulnerability map was broader in its scope, as food security datasets were just one component in wide range of cross-sectoral datasets used. Learning from the Niger experience, in Burkina Faso the vulnerability map was accompanied by explanations of structural vulnerability, which was clearly defined upfront as a tendency to be in a state of high-risk to negative well-being outcomes (i.e., undernutrition, anaemia) on account of persistent exposure to various potential shocks (i.e., climatic, price) in combination with a chronic resilience deficit (i.e., lack of absorptive, adaptive and transformative capacities). 
In Niger a few key impacts can be highlighted. First, the government of Niger, along with some partners and donors, are using the map to help guide decisions regarding longer term resilience investments. The map has also been a useful tool in terms of generating fruitful discussions among various in-country stakeholders about the dynamics and determinants of vulnerability in Niger. One interesting observation during some discussions was that geographic zones of social vulnerability appear to correlate fairly well with areas of conflict and instability, suggesting that interventions aimed at increasing social justice may help to counter violent extremism.

As a further illustration of the demonstration effect, after becoming aware of the Burkina Faso vulnerability map, the Government of Mauritania expressed interest in creating a climate vulnerability map. To increase perceived legitimacy, a mapping working group, led by the Ministry of Economic Affairs and Development and with a cross-section of donors and government representatives oversaw map development.

\section{West Africa}

The coastal West Africa maps were requested and completed as one component of a larger set of vulnerability studies designed to inform the development of the West African Biodiversity and Climate Change (WA BiCC) programme. Given the size and complexity of the region and based on the results of a series of desk studies and numerous discussions among USAID staff conducted prior to the mapping, it was decided that the mapping component would focus on the coastal zone. However, no sector was prioritized. Instead the focus was more generally on the potential negative social and economic impacts associated with coastal climate change impacts (i.e., storm surge, coastal floods, and sea level rise). The focus of the vulnerability index was thus on the "defencelessness" of populations exposed to these stressors, and included factors such as poverty, population density, population growth, conflict incidence, and maternal education levels (Figure 2). The IPCC risk framework (IPCC 2012) was 
used in this case, since risk is seen to emanate from a confluence of exposure, hazard and social vulnerability.

[FIGURE 2 HERE]

It was felt that the maps and the underlying data collection effort should provide both an initial sense of what data are available at the regional level and how different factors (e.g., exposure, social and economic sensitivity) varied in coastal West Africa. As this assessment was meant to inform the development of the WA BiCC programme, there was strong interest in understanding how climate change could impact important coastal ecosystems such as mangroves and estuaries that contain high levels of biodiversity. These maps were not only intended to help inform USAID's internal strategic thinking in the development of this new programme, they were also intended to be shared widely with other stakeholders. USAID saw the maps as helping fill what they perceived as a gap in available geographic information in West Africa, and thus a very strong demand for maps.

While the maps were under development, USAID supported a regional West and Central Africa workshop on mangroves. Initial versions of the maps showing the distribution of mangroves as well as variations of the Social Vulnerability Index and the Economic Sensitivity Index were provided as contextual inputs to the workshop. The maps were well received by the workshop participants, and several participants (including regional institutions) requested high resolution electronic versions of the maps for use in their own strategic decision planning processes. ${ }^{1}$ The maps were also used in the design of WA BiCC, helping inform discussions associated with conceptualization, design, and targeting of the programme.

${ }^{1}$ These are available at http://ciesin.columbia.edu/data/wa-coastal/. 


\section{Discussion}

\section{Demand for maps in policy contexts}

It is clear from all four mapping efforts that there is a high demand for maps in West Africa. This is consistent with what prior vulnerability mapping exercises have found (e.g., Preston et al. 2009), but it is perhaps accentuated here by a perceived lack of spatial data on social and environmental parameters in the region. While data do in fact exist for many parameters, it appears that they are not widely accessible, used, or represented in map form. The maps serve as a knowledge management tool in helping to see the whole picture of available data at once, something that was found to be of value to high level decision makers.

In addition, the simplicity of the maps played a key role in their use. Most of the audiences to which these maps were presented had a strong familiarity with maps as a visual medium. Given the time constraints under which many high level decision makers operate, there is a high demand for tools that quickly and clearly convey essential information. These maps also provided an excellent tool through which to start conversations and build interest in climate change, which is often viewed as complex. On the other hand, with simplicity comes a corresponding risk that the critical assumptions and uncertainties are masked (Preston et al. 2011). This is why documentation of methods, underlying data, and assumptions is so important (de Sherbinin 2014a). However, each mapping effort took slightly different approaches to conveying this underlying information, and it still remains to be seen which approach is the most effective. From initial observations it appears that all approaches have their advantages and disadvantages, and no one method will be satisfactory to all potential policy audiences.

\section{Factors affecting use and acceptance}

Returning to the ingredients affecting uptake mentioned above, credibility, salience and legitimacy, we found that users readily accepted the maps as credible and based on best available data 
and methods. This is partially based on the credibility of the source (i.e., CIESIN) of the geospatial methods and data integration tools. Those USAID staff who participated in map development and understood the statistical methods behind the maps were able to assess the soundness of the methods as well as the underlying uncertainties. In this regard, use of alternative aggregation methods (PCA) and sensitivity analysis, together with documentation of all data sources, helped to increase user confidence in the overall results.

Issues associated with salience and legitimacy are a bit harder to evaluate. For the purposes of this paper, salience is defined to include both relevance and timeliness. As mentioned, in the case of Mali significant interest and usage of the maps resulted from a confluence of factors that significantly enhanced their salience. The Mali maps were intended primarily as an internal document to help with geographic targeting. This targeting was facilitated by a fairly narrow and clear definition of vulnerability (i.e., vulnerability of subsistence agriculture to temperature increases and changes in rainfall). The ability to define the purpose clearly allowed the final maps to be highly relevant to the decisions being made by USAID. The relevance was further enhanced by the fact that the scope of the assessment was aligned with the available budget, allowing the underlying methodology and data collection to be fairly robust and results to be tailored to the decisions to be made, thus further increasing the relevance.

Conversely, for the West Africa study the system to be mapped was less clearly bounded. For example, the assessment had to confront challenges associated with defining the extent of the coastal zone, the differential vulnerability of large cities versus rural areas, differential vulnerability among important sectors along the coast, and data inconsistencies among the countries being assessed. Therefore, given the large and non-homogenous geographic area and the complex sectoral framework, the maps could only provide an initial sense of how different social and economic systems might be exposed to coastal stressors. The lack of a single "hotspot" or vulnerability map may have reduced the 
ultimate relevance of the maps to USAID. This suggests that the relevance of mapping efforts may be contingent on being able to clearly define the problem and system to be mapped.

Timeliness also played a key role in the eventual use of the maps. The maps constructed for Mali had clear decision points and processes to influence, and the time frame for each was clearly defined. Thus while there was a need to develop these maps quickly, interest remained high in these maps through the important decision points. On the other hand, while the maps developed for West Africa were also meant to inform an ongoing process, the time frame associated with that process was less clear and interest in the maps varied over the mapping effort. This suggests that key decision points provide an opportunity to gain the attention of the key audience and increase the saliency of the maps.

The Niger and Burkina Faso maps were considered highly salient, but for slightly different reasons. Vulnerability mapping in Niger was particularly timely in light of the security issues the country faces. In this regard, there was some tendency to over-interpret the map as a conflict vulnerability map even though the documentation was clear that conflict events were only one of 21 indicators. The Burkina Faso map was very timely in that it was released shortly after a fresh government transition coming out of a citizen-led revolution. A greater optimism after this revolution may have led to more interest and a general feeling of timeliness and salience surrounding the map.

Limited budgets in all cases meant that there was no broad stakeholder engagement in the development of these maps in terms of indicator selection, weighting, or other aspects. Had the maps represented relatively localized areas at a high spatial resolution, this lack of stakeholder engagement probably would have raised more questions about inclusion and legitimacy. Previous studies have demonstrated that engaging local decision makers in the entire process of map generation can increase interest in and uptake of the final maps (Preston et al. 2009). Yet participation can also slow the process. As it was, given that the maps covered whole countries/regions, consultation with USAID staff - and, in 
the case of Niger and Burkina Faso, selected government departments and donors - was considered sufficient for USAID internal users. Furthermore, the fact that most of the maps re-enforced preconceived beliefs of how vulnerability varied within these countries probably prevented more questions concerning the legitimacy of these maps.

\section{Maps are only part of the input to the Analytical Process}

As mentioned above, all the vulnerability mapping exercises were part of larger vulnerability studies or analytical processes. While vulnerability maps are an important tool for building interest in and understanding of geographic variations in vulnerability, they do not necessarily answer the question of what needs to be done to reduce vulnerability or how to build resilience. Furthermore, while it may be possible to understand some of the underlying factors leading to the broad geographic variations in vulnerability by examining the different layers or individual indicators used, the maps were too generalized to address the factors that determine individual, household and even community-level vulnerability.

Therefore, vulnerability maps, at least when conducted at this scale, are most effective when they complement other analytical components. These can be other national or regional scale components to identify relevant institutional structures, or follow-on components targeting specific geographic areas or sectors identified through the maps where potential adaptive options can be further

examined. For example, in Mali, further analytical studies were undertaken in the Mopti region once the maps were used to identify that as the region of highest interest, allowing for a deeper analysis with limited resources. While maps can capture the attention among policy audiences, they should be used as an entry rather than an end point, in terms of understanding the vulnerability-generating mechanisms and the most viable policy responses. 


\section{Discussion and Ways Forward}

In the preceding sections we have documented ways in which maps appeared to influence donor decision-making in three contexts. This was admittedly a subjective and biased review of the evidence: two of the authors were involved in map production, and two were involved in or direct witnesses to the decision-making processes within USAID. There is clearly a need for more objective and rigorous assessments of the value and impact of vulnerability mapping (and spatial data more generally) in decision-making processes. Key questions that further research could address include the following: Do decision makers interpret maps in a way that is consistent with the communication intent of the map authors (e.g., Ishikawa et al. 2005, Clarke 2003)? What additional information do decision makers bring to their interpretation? What level of confidence and trust do they have in the maps as decision-support tools, and how sceptical are they about the impacts that are portrayed and why? How do results conform or diverge from their mental maps, and how does that affect their perceived legitimacy? What are the most effective ways to communicate the multiple sources of uncertainty (e.g. Kaye et al. 2012, MacEachren et al. 2005)?

While a full review of available approaches to answer these questions is beyond the scope of this paper, we suggest some ways forward to assess more rigorously the policy influence and application of vulnerability maps. These could include: (a) semi-structured individual or focus group interviews; (b) work observation; (c) think aloud protocols (whereby subjects will verbally express what they are thinking about as they explore maps); (d) online focus group or Delphi exercises (MacEachren et al. 2006); and (e) task analysis. The aim would be to gauge policy-maker comprehension of the information presented in maps, their preferences in map design (Retchless and Brewer 2015), their comfort level with the uncertainty in map products, and, ultimately, how and why the information presented in maps influenced their decisions. In addition, emerging approaches to measuring the value of information can 
help researchers to understand the socio-economic benefits of vulnerability mapping (NASA 2012).

Ideally, assessments of this sort would be conducted by third parties, and not by those involved in the map production or decision making processes.

\section{Conclusion}

This article describes one regional and three country-level vulnerability mapping studies in West Africa with a particular focus on the uptake of results by end users as observed by the authors. The maps were prepared for different purposes, but broadly sought to identify areas of highest relative vulnerability within the region owing to socio-economic and bio-physical factors.

Vulnerability assessments have become a primary mechanism for elucidating the complex factors that contribute to local susceptibility to climate impacts (PROVIA 2013). Yet, technically rigorous and detailed scientific assessments can be difficult for non-technical audiences to understand. This in turn can reduce interest in and use of such assessments. Vulnerability maps have an advantage as a communication tool in that they simplify complex realities (Abson et al. 2012). In so doing, they can act as the entry way for the more technical aspects of in-depth sectoral assessments. In our own work, the maps helped to engage USAID staff with different development portfolios in Mali, facilitated conversations between development and humanitarian stakeholders in Niger and have generated broad interest and discussions amongst a range of stakeholders in Burkina Faso.

With the power of maps also comes responsibility. The very power of maps, which is to simplify complex ground-based realities by abstracting information, may give them inordinate influence among policy audiences (Preston et al. 2011), even though they have the potential to lead to wrong conclusions. For example, it would be wrong to conclude that low relative vulnerability in the urban areas of the Sahelian countries means that populations there are not at all vulnerable to climate change 
impacts and therefore are undeserving of adaptation interventions. It is important to ensure there is a clear articulation of the purpose of the maps (in the Sahel case - to illuminate vulnerability of the agricultural sector to climate change) as well as limitations and uncertainty embedded within the maps (de Sherbinin 2014a). We were able to fairly clearly trace the availability of the maps to specific USAID policy decisions. As geographic information for priority setting is often a favoured option among policy audiences (e.g., BMZ 2014, de Sherbinin 2014b), it will be important to refine vulnerability mapping methods and to continue studying the manner in which maps are assimilated into policy making processes and used to inform decisions. ${ }^{2}$

\section{References}

Abson D J Dougill A J and Stringer L C 2012 Using Principal Component Analysis for information-rich socio-ecological vulnerability mapping in Southern Africa Applied Geography 35 515-524

Antwi-Agyei P Dougill A J Fraser E D G and Stringer L C 2013 Characterising the nature of household vulnerability to climate variability: empirical evidence from two regions of Ghana Environment, Development and Sustainability 15 903-926

Birkmann J and B Wisner 2006 Measuring the Un-Measurable: The Challenge of Vulnerability UNU-EHS SOURCE $n 5$ United Nations University-Environment and Human Security, Bonn

Blarney R Coop L Jack C Loveday B and Sutherland K 2013 Background Paper on the Status and Possible Evolution of Climate Projections in West Africa Technical Paper for the USAID African and Latin American Resilience to Climate Change (ARCC) project, USAID, Washington DC

BMZ (German Federal Ministry for Economic Cooperation and Development) 2014 The Vulnerability Sourcebook: Concept and guidelines for standardised vulnerability assessments GIZ (Deutsche Gesellschaft fur Internationale Zusammenarbeit), Berlin

Bradshaw G A and Borchers J G 2000 Uncertainty as information: narrowing the science-policy gap

\footnotetext{
${ }^{2}$ This is the purpose of ongoing work by the lead authors under a Socio-Environmental Synthesis Center (SESYNC) project, "MetaAnalysis of Climate Change Vulnerability Mapping Studies". See http://www.sesync.org/project/pursuit/climate-changevulnerability-mapping-studies
} 


\section{Conservation Ecology 47}

Busby J W Smith T G White K L and Strange S M 2013 Climate change and insecurity: Mapping vulnerability in Africa International Security 37 132-172

Cash D W Clark W C Alcock F Dickson N M Eckley N Guston D Jager J and Mitchell R 2003 Knowledge systems for sustainable development Proceeding of the National Academy of Science 100 8086-8091 Chaudhury M Dinshaw A and McGray H 2014 Designing Climate Vulnerability Assessments for Decisionmaking Uptake: A Conceptual Framework and Case Examples Technical Paper for the USAID African and Latin American Resilience to Climate Change (ARCC) project, USAID, Washington DC Clarke D 2003 Are you functionally map literate? Proceedings of the 21st International Cartographic Conference, International Cartographic Association (ICA), 10-16 August 2003, Durban, South Africa Densham P J 1991 Spatial decision support systems Geographical information systems: Principles and applications 1 403-412

de Sherbinin A Chai-Onn T Jaiteh M Mara V Pistolesi L Schnarr E and Trzaska S 2015 Data Integration for Climate Vulnerability Mapping in West Africa ISPRS International Journal of Geo-Information 4 25612582

de Sherbinin A 2014a Spatial Climate Change Vulnerability Assessments: A Review of Data, Methods and Issues Technical Paper for the USAID African and Latin American Resilience to Climate Change (ARCC) project, USAID, Washington DC

de Sherbinin A 2014b Mapping the unmeasurable? Spatial Analysis of Vulnerability to Climate Change and Climate Variability PhD dissertation published by the Faculty for Geo-Information Sciences and Technology, University of Twente, Netherlands

de Sherbinin A Chai-Onn T Giannini A Jaiteh M Levy M Mara V Pistolesi L and Trzaska S 2014a Mali Climate Vulnerability Mapping Technical Paper for the USAID African and Latin American Resilience to Climate Change (ARCC) project, USAID, Washington, DC

de Sherbinin A Chai-Onn T Jaiteh M Mara V Pistolesi L and Schnarr E 2014b Mapping the Exposure of Socio-economic and Natural Systems of West Africa to Coastal Climate Stressors Technical Paper for the USAID African and Latin American Resilience to Climate Change (ARCC) project, USAID, Washington, DC de Sherbinin A Levy M Zell E Weber S and Jaiteh M 2014c Using Satellite Data to Develop 
Environmental Indicators Environmental Research Letters 9084013

de Sherbinin A 2013 Climate Change Hotspots Mapping: What Have We Learned? Climatic Change 123 23-37

Feick R D and Hall G B 2001 Balancing consensus and conflict with a GIS-based multi-participant, multicriteria decision support tool GeoJournal 53 391-406

Hezri A A 2004 Sustainability indicator system and policy process in Malaysia: A framework for utilisation and learning Journal of Environmental Management 73 357-371

Hezri A A and Dovers S R 2006 Sustainability indicators, policy and governance: Issues for ecological economics Ecological Economics 60 86-99

Hinkel J 2011 "Indicators of vulnerability and adaptive capacity": Towards a clarification of the sciencepolicy interface Global Environmental Change 21 198-208

IPCC (Intergovernmental Panel on Climate Change) 2012 Managing the risks of extreme events and disasters to advance climate change adaptation in Field C B et al eds A Special Report of Working Groups I and II, IPCC, Cambridge

Ishikawa T Barnston A G Kastens K A et al 2005 Climate forecast maps as a communication decisionsupport tool Cartography and Geographic Information Science 32 3-16

Kaye N R Hartley A and Hemming D 2012 Mapping the climate: guidance on appropriate techniques to map climate variables and their uncertainty Geoscience Model Development 5 245-256

Klein R T 2009 Identifying countries that are particularly vulnerable to the adverse effects of climate change: an academic or a political challenge? Carbon and Climate Law Review 3 284-291

López-Carr D Pricope N G Aukema J E Jankowska M M Funk C Husak G and Michaelsen J 2014 A spatial analysis of population dynamics and climate change in Africa: potential vulnerability hot spots emerge where precipitation declines and demographic pressures coincide Population and Environment $35323-$ 339

MacEachren A M Pike W Yu C et al 2006 Building a GeoColloaboratory Computers, Environment and Urban Systems 30 201-225

MacEachren A M Robinson A Hopper S et al 2005 Visualizing Geospatial Information Uncertainty: What We Know and What We Need to Know Cartography and Geographic Information Science 32 139-160 
McNie E 2006 Reconciling the supply of scientific information with user demands: an analysis of the problem and review of the literature Environmental Science \& Policy $1017-38$

Midgley S J E Davies R A G and Chesterman S 2011 Climate risk and vulnerability mapping in southern Africa: status quo (2008) and future (2050) Report produced for the Regional Climate Change Programme for Southern Africa (RCCP), UK Department for International Development (DFID), OneWorld Sustainable Investments, Cape Town

NASA 2012 Measuring Socio-economic Impacts of Earth Observations, US Government Printing Office, Washington DC

Nelson R Kokic P Crimp S Meinke H Howden S M 2010 The vulnerability of Australian rural communities to climate variability and change: Part I-Conceptualising and measuring vulnerability Environmental Science \& Policy 13 8-17

OECD (Organization for Economic Cooperation and Development) and JRC (Joint Research Centre of the European Commission) 2008 Handbook on Constructing Composite Indicators, OECD, Paris Parry M L Canziani O F Palutikof J P van der Linden P J and Hanson C E 2007 Climate Change 2007: Impacts, Adaptation and Vulnerability Contribution of Working Group II to the Fourth Assessment Report of the Intergovernmental Panel on Climate Change, IPCC, Cambridge

POINT (Policy Use and Influence of Indicators) 2011 A synthesis of the findings of the POINT project No 15 POINT Policy use and influence of indicators - Current use of and emerging needs for indicators in policy, The Bayswater Institute

Preston B L Yuen E J and Westaway R M 2011 Putting vulnerability to climate change on the map: a review of approaches, benefits, and risks Sustainability Science 6 177-202

Preston B Brooke C Measham T Smith T and Gorddard R 2009 Igniting change in local government: lessons learned from a bushfire vulnerability assessment Mitigation and Adaptation Strategies for Global Change, 14, 251-283

PROVIA (Programme on Vulnerability, Impacts and Adaptation) 2013 PROVIA Guidance on Assessing Vulnerability, Impacts and Adaptation to Climate Change United Nations Environment Programme, Nairobi

Retchless D P and Brewer C A 2015 Guidance for representing uncertainty on global temperature 
change maps International Journal of Climatology 36 1143-1159

Sabatier P and Jenkins-Smith H C 1993 Policy Change and Learning: An Advocacy Coalition Approach, Westview Press, Boulder

Tschakert P 2007 Views from the vulnerable: Understanding climatic and other stressors in the Sahel, Global Environmental Change 17 381-396

Turco M Palazzi E von Hardenberg J and Provenzale A 2015 Observed climate change hotspots Geophysical Research Letters 42

USAID (United States Agency for International Development) 2012 Climate Change and Development Strategy, USAID, Washington DC

USGCRP (US Global Change Research Programme) 2012a Climate Change Impacts and Responses: Societal Indicators for the National Climate Assessment NCA Report Series, Volume 5c, US Government Printing Office, Washington DC

USGCRP (US Global Change Research Programme) 2012b Ecosystem Responses to Climate Change: Selecting Indicators and Integrating Observational Networks NCA Report Series, Volume 5a, US Government Printing Office, Washington DC

USGS and USAID (United States Geological Survey and United States Agency for International Development) 2012 A Climate Trend Analysis of Mali, Informing Climate Change Adaptation Series, Famine Early Warning Systems Network (FEWS NET), US Government Printing Office, Washington DC 

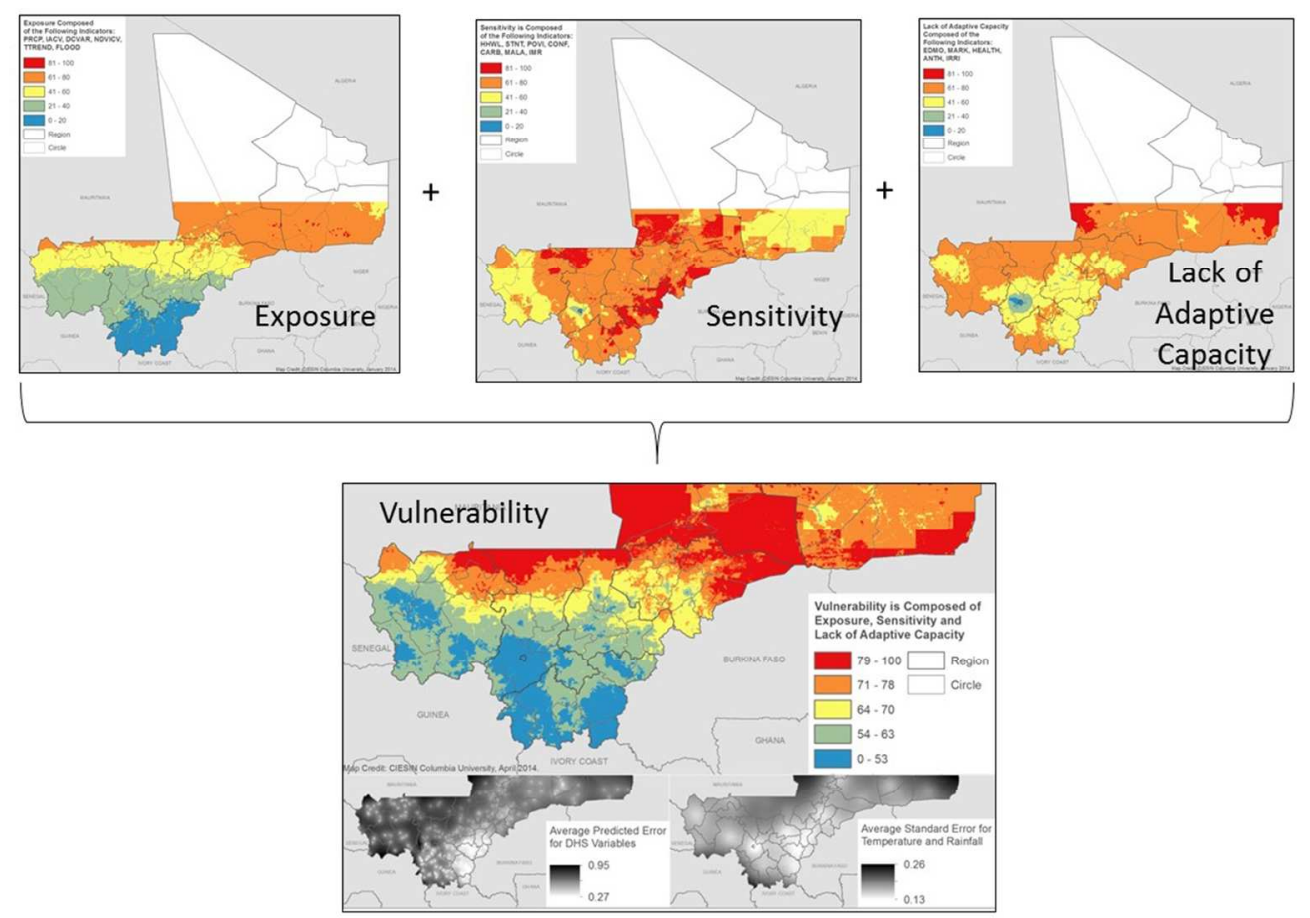

Figure 1. Mali vulnerability map. Components of vulnerability rolled up into an overall vulnerability index $301 \times 211 \mathrm{~mm}(96 \times 96 \mathrm{DPI})$ 
Figure 2. Social Vulnerability Index and cities in relation to the West Africa Low Elevation Coastal Zone. Urban areas are particularly exposed to storm surge and potential future sea level rise. 


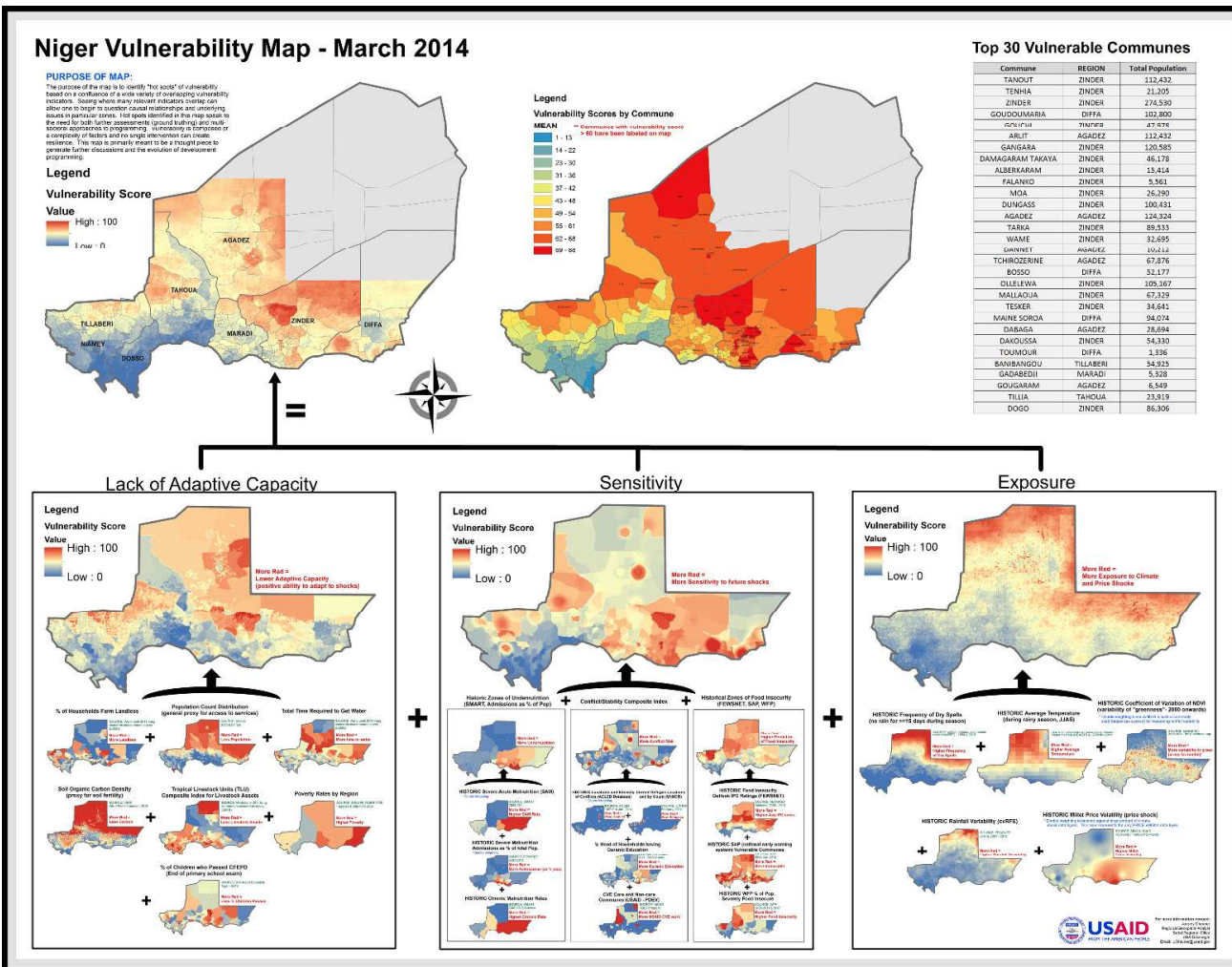

Figure SI1. Niger poster map illustrating the many indicators that were combined to create an overall vulnerability index 2469x1920mm (72 x 72 DPI) 